\title{
NOVOS TÁXONS DE DISTENIIDAE (COLEOPTERA) NEOTROPICAIS
}

\author{
Ubirajara R. Martins ${ }^{1,3}$ \\ Maria Helena M. Galileo ${ }^{2,3}$
}

\begin{abstract}
NEW TAXA OF NEOTROPICAL DISTENIIDAE (COLEOPTERA). New taxa described: Cometes soledari (Bolivia, Beni), Paracometes amabilis (Costa Rica), P. pojuca (Brasil, Pará) and Aiurasyma gen. nov., type-species, A. potira sp. nov. (Colombia).

KEYWORDS. Coleoptera, Disteniidae, Neotropical, Taxonomy.
\end{abstract}

\section{INTRODUÇÃO}

Os Disteniidae das Américas foram estudados por ViLLIERs (1957), que propôs a divisão do gênero Cometes Lepeletier \& Audinet-Serville, 1828, em três gêneros: Microcometes, Pseudocometes e Paracometes. Em artigos imediatamente posteriores, (VILLIERS, 1958a, b) reviu os gêneros Pseudocometes e Paracometes e, em 1959, apresentou um ensaio sobre as espécies americanas de Distenia Lepeletier \& Audinet-Serville, 1828.

Neste trabalho são descritas novas espécies e um gênero novo de Disteniidae, constatados durante o trabalho de rotina de identificação para as seguintes instituições: Carnegie Museum of Natural History, Pittsburgh (CMNH), Museu Paraense Emílio Goeldi, Belém (MPEG) e Museu de Zoologia, Universidade de São Paulo, São Paulo (MZSP).

1. Museu de Zoologia, Universidade de São Paulo; Caixa Postal 42594; CEP 04299-970 São Paulo, SP, Brasil.

2. Museu de Ciências Naturais, Fundação Zoobotânica do Rio Grande do Sul; Caixa Postal 1188; CEP 90001-970 Porto Alegre, RS, Brasil.

3. Pesquisador do CNPq. 


\section{Cometes soledari sp. nov.}

(Fig. 1)

Etimologia. Homenagem a Jorge Dutra Soledar (Museu de Ciências Naturais, Fundação Zoobotânica do Rio Grande do Sul, Porto Alegre) como reconhecimento pelas fotografias e desenhos que têm ilustrado nossos trabalhos.

Macho. Cabeça preta com reflexo metálico esverdeado. Pontuação grossa e densa, exceto na região gular com tegumento liso. Sutura coronal bem demarcada. Presença de setas esbranquiçadas atrás dos olhos e, na fronte, perto do olhos. Antenas pretas, atingem a extremidade elitral na ponta do antenômero VII. Protórax preto com reflexos verdemetálicos; sulcos anteapical e antebasal demarcados e profundos. Pontuação grossa, densa, os pontos contíguos, exceto área centro-longitudinal na metade basal, lisa. Lados do protórax com espinho pouco atrás do meio. Disco pronotal com quatro gibosidades. Processo prosternal estreito. Esternos torácicos com pontuação grossa e com setas esbranquiçadas. Processo mesosternal quase tão largo quanto uma mesocoxa. Metasterno com pontos grossos nos lados. Escutelo preto. Élitros (fig. 1) amarelados com uma área preta, longitudinal, dorsal, alongada, que se inicia junto ao escutelo e vai até o terço basal; terço apical preto com reflexos violáceos. Pontuação elitral grossa em toda superfície. Setas sobre a área preta apical. Duas costas pouco indicadas em cada élitro. Pernas amareladas. Tarsômero V escurecido.

Dimensões, em mm. Comprimento total, 11,3; comprimento do protórax, 1,7; maior largura do protórax, 2,0; comprimento do élitro, 8,0; largura umeral, 2,5.

Material-tipo. Holótipo ớ, BOLÍVIA, Beni, Uyapi, Guanay, X-XI.1992, L. Peña col. (MZSP).

Discussão. Cometes soledari assemelha-se a Cometes argodi Belon, 1896, também procedente da Bolívia. Distingue-se principalmente pela cor das pernas inteiramente amarelada; pelo brilho metálico na cabeça, no pronoto e nas regiões escuras dos élitros; pela ausência de faixa preta que vai, junto à margem, desde o úmero até o terço anterior e pelo escutelo preto. No holótipo de Cometes argodi, as pernas são pretas com exceção da base dos profêmures e as articulações de todas as tíbias que são amareladas; a cabeça, o protórax e o terço apical dos élitros são pretos, sem reflexos metálicos; existe uma faixa longitudinal, preta, junto à margem, do úmero até o terço anterior, e o escutelo é testáceo.

\section{Paracometes amabilis sp. nov.}

(Fig. 2)

Macho. Cabeça azul-arroxeada com reflexos metálicos. Vértice esparsamente pontuado; sutura coronal bem evidente do meio dos lobos oculares para atrás, ladeada por finas rugas subtransversais $(50 \mathrm{x})$ e terminada em pequena fóvea. Face inferior da cabeça lisa. Escapo arroxeado, mais azulado na base. Pedicelo e flagelômeros pretos. Flagelômeros III a XI esbeltos. Protórax azul-arroxeado com reflexos metálicos. Pronoto com cinco tubérculos dos quais os dois anteriores são os maiores; interstícios grosseiramente pontuados. Partes laterais do protórax com tubérculo desenvolvido próximo do meio. Prosterno liso. Escutelo azulado com reflexos metálicos. Élitros (fig. 2) com a região circum-escutelar arroxeada; restante do terço anterior amarelado; região central ocupada por faixa azul-arroxeada com reflexos metálicos, subtransversal e com as bordas levemente irregulares; terço apical amarelado. Pontuação elitral fina, presente em toda a 
superfície. Extremidades elitrais acuminadas. Face inferior do corpo com reflexos azulados e metálicos, principalmente, nas partes laterais. Pernas pretas. Pêlos brancos nas partes laterais do protórax, no lado inferior dos fêmures e na face ventral do corpo.

Dimensões, em mm. Comprimento total, 10,7; comprimento do protórax, 1,7; maior largura do protórax, 1,9; comprimento do élitro, 8,0; largura umeral, 2,3.

Material-tipo. Holótipo ó, COSTA RICA, San José, 27.VI.1925, Schmidt col. (CMNH).

Discussão. Paracometes amabilis sp. nov. assemelha-se, pela chave de VILLIERS (1958b), a P. biplagiatus Villiers, 1958 e a P. festivus Bates, 1885. Distingue-se de $P$. biplagiatus pelo padrão de colorido dos élitros; pela pontuação dos interstícios dos tubérculos do disco pronotal com mais de uma fileira de pontos e pelos ápices elitrais acuminados. Em P. biplagiatus, o terço apical de cada élitro é violáceo; os ápices elitrais são ovalares; as gibosidades do disco pronotal são separadas por apenas uma fileira de pontos.

Difere de $P$. festivus pelo colorido geral azul-arroxeado, pela faixa mediana dos élitros de mesma cor e não-projetada na sutura em direção à base e ao ápice; além disso, a região circum-escutelar é ocupada por pequena área azul-arroxeada. Em $P$. festivus, o colorido geral é verde com reflexos metálicos; a faixa central dos élitros projeta-se, ao longo da sutura, para a base e para o ápice e não existe mancha circum-escutelar.

\section{Paracometes pojuca sp. nov.}

(Fig. 3)

Etimologia. Alusivo à localidade-tipo, Igarapé Pojuca.

Fêmea. Tubérculos anteníferos castanhos e lisos. Vértice esverdeado com reflexos metálicos e pontuado. Gula acastanhada e lisa. Lobos oculares superiores mais próximos entre si do que a largura de um lobo. Antenas pretas. Protórax mais largo do que longo (espinhos laterais inclusive), bem constrito perto da margem anterior; constrição basal menos acentuada. Pronoto com gibosidades muito discretas; a central, longitudinal, mais próxima da base e com tegumento liso; restante da superfície pronotal pontuada. Espinho lateral acuminado, situado para trás do meio. Meio do prosterno com sulco transversal profundo; metade posterior com tegumento alaranjado; processo prosternal acuminado para o ápice. Mesosterno e metasterno alaranjados; lados do metasterno mais escurecidos e grosseiramente pontuados. Escutelo castanho-avermelhado sem reflexo metálico. Élitros (fig. 3) castanho-arroxeados com brilho metálico; mancha amarelada na base de cada élitro, envolve os úmeros, mas não alcança o escutelo; pontuação muito densa em toda a superfície; costas discretas; extremidades individualmente arredondadas. Coxas e trocanteres com tegumento amarelado; profêmures amarelados e, na metade dorsal, acastanhados; meso- e metafêmures com a metade basal alaranjada e a metade apical acastanhada; tíbias pretas mais acastanhadas em pequena porção basal. Urosternitos com a área central vermelho-acastanhada e, nos lados, azuis escuros com brilho metálico.

Dimensões, em mm. Comprimento total, 9,5; comprimento do protórax, 1,5; maior largura do protórax, 1,9; comprimento do élitro, 6,8; largura umeral, 2,1.

Material-tipo. Holótipo Y, BRASIL, Pará, Serra Norte (Igarapé Pojuca), 4.XI.1983, (armadilha suspensa a $2 \mathrm{~m}$ de altura) (MPEG). O pedicelo esquerdo do holótipo apresenta uma anomalia teratológica.

Discussão. Villiers (1957) comparou os gêneros Paracometes e Pseudocometes. Em Pseudocometes: lobos oculares superiores muito aproximados entre si no vértice; 
antenas "relativement fortes" (VILLIERS, 1957: 413); palpos maxilares dos machos com o artículo IV dotado de longo apêndice pubescente perto da base. Para Paracometes não foram definidos os lobos oculares superiores; antenas "assez fines sans épaississement notable" (VILLIERs, 1957: 412); palpos dos machos sem modificações. Esses caracteres variam e, em Paracometes scapularis (Bates, 1870) por exemplo, que deveria ter antenas sem espessamento, os flagelômeros são bastante engrossados. Parece então que o caráter mais óbvio para diferenciar os dois gêneros é a forma do artículo IV dos palpos dos machos.

Só conhecemos uma fêmea de Paracometes pojuca, portanto sua colocação em Paracometes é incerta. Preferimos inserí-la neste gênero por exclusão, isto é, por não coincidir com a descrição de nenhuma das quatro espécies conhecidas em Pseudocometes. Duas delas têm fêmures com base testácea: Pseudocometes bicoloripes Villiers, 1958 e P. argutulus (Buquet, 1851). A mancha amarelada da base dos élitros emP. bicoloripes é mais extensa e os ápices são acuminados no ângulo sutural, enquanto que em Paracometes pojuca a mancha é menor, restrita aos ombros, e o ápice elitral é arredondado. $O$ desenho dos élitros é bem semelhante ao de Pseudocometes argutulus que, segundo VILLIERS (1957: 38), tem o pronoto forte e densamente pontuado, com cinco gibosidade lisas e a base dos fêmures alaranjada. Em Paracometes pojuca o pronoto apresenta cinco gibosidades, das quais somente a central é lisa e toda a face ventral é avermelhada, com urosternitos azulados nos lados; coxas, trocanteres e grande extensão dos fêmures, amarelados.

Pela chave de Paracometes publicada por VILLIERS (1958b), P. pojuca assemelha-se a $P$. flavipes Villiers, 1958 pela coloração das pernas. Em P. flavipes, as pernas são inteiramente amareladas e os élitros têm o terço basal amarelado; em P. pojuca as pernas são parcialmente escuras e os élitros são amarelados apenas nos lados da base e em pequena extensão, com faixa da coloração de fundo até o escutelo (fig. 3).

\section{Aiurasyma gen. nov.}

Etimologia. Tupi, aiura=pescoço; syma = liso; alusivo ao protórax desarmado. Espécie-tipo, Aiurasyma potira, sp. nov.

Vértice com pontos muito abundantes e pontos anastomosados. Último artículo do palpo maxilar com ápice truncado e grande área apical aprofundada e provida de pubescência fina e densa. Olhos finamente granulados. Lobos oculares superiores mais distantes entre si do que o diâmetro de um lobo. Antenas tão longas quanto o corpo nos machos. Escapo engrossado para o ápice, levemente curvo na base, um terço mais longo do que o antenômero III. Flagelômeros sem longos pêlos na margem interna. Antenômeros III a X com comprimentos subiguais. Antenômero XI mais longo do que o precedente. Protórax tão longo quanto largo, com as contrições anterior e posterior de largura subigual. Lados do protórax apenas gibosos, sem espinhos. Pronoto com dois tubérculos arredondados no topo ao nível do terço anterior; restante da superfície densamente pontuada. Processo prosternal regularmente curvo; largura entre as coxas subigual ao quarto do diâmetro de uma procoxa. Processo mesosternal pouco mais estreito do que uma mesocoxa. Cavidades coxais anteriores fechadas atrás. Pontuação elitral grosseira, no dorso organizada em fileiras longitudinais. Extremidades elitrais arredondadas. Lados do metasterno e urosternitos com pontuação moderada. Fêmures fusiformes. 

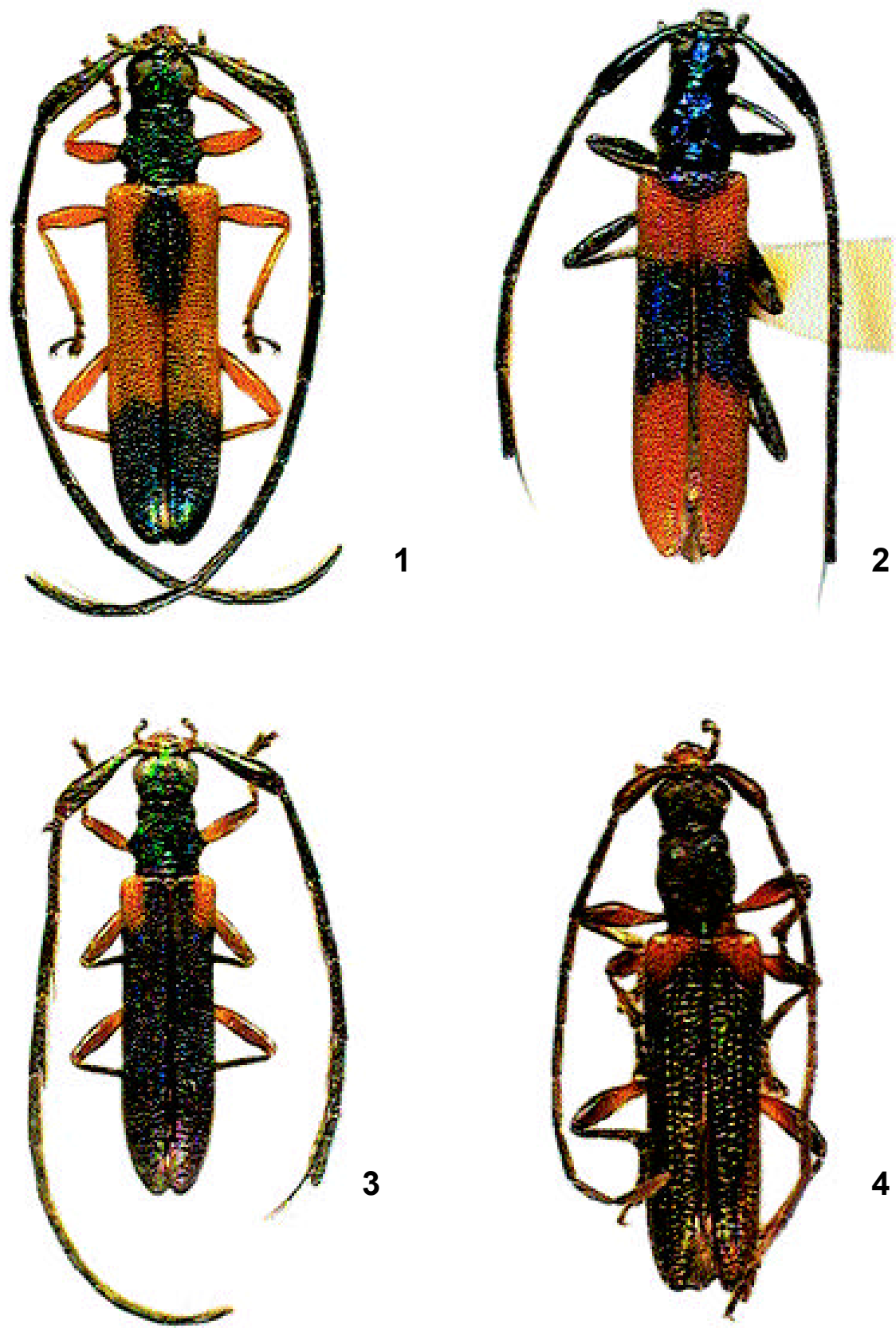

Figs. 1-4. 1, Cometes soledari sp. nov., holótipo 1 , comprimento $11,3 \mathrm{~mm} ; 2$, Paracometes amabilis sp. nov., holótipo $\rightarrow$, comprimento $10,7 \mathrm{~mm}$; 3, P. pojuca sp. nov., holótipo 1 , comprimento 9,5 mm; 4, Aiurasyma potira sp. nov., holótipo -1 , comprimento $7,9 \mathrm{~mm}$. 
Discussão. Aiurasyma gen. nov. difere de todos os demais gêneros americanos de Disteniidae pelo último artículo dos palpos maxilares dos machos obliquamente truncado no ápice e com grande área deprimida e pubescente; pelas antenas sem pêlos longos, com escapo mais longo do que o antenômero III; antenômeros III-X curtos, com comprimentos subiguais; protórax desarmado nos lados; pronoto com dois tubérculos desenvolvidos ao nível do terço anterior e cavidades coxais anteriores fechadas atrás.

\section{Aiurasyma potira sp. nov.}

(Fig. 4)

Etimologia. Tupi, potyra = flor d'água. Homenagem a Potira Viegas Preiss, Museu de Ciências Naturais, Fundação Zoobotânica do Rio Grande do Sul.

Macho. Cabeça, antenas, protórax e face ventral do corpo, castanho-avermelhados. Élitros castanho-avermelhados com ligeiro reflexo esverdeado-metálico. Úmeros (fig. 4) com mancha amarelada que não atinge o escutelo. Fêmures amarelados e acastanhados na metade apical da face dorsal. Tíbias amareladas, escurecidas no extremo da base. Face ventral com pêlos esbranquiçados, esparsos.

Dimensões, em mm. Comprimento total, 7,9; comprimento do protórax, 1,4; maior largura do protórax, 1,4; comprimento do élitro, 5,6; largura umeral, 1,9. (CMNH)

Material-tipo. Holótipo ớ, COLÔMBIA, Magdalena, Valparaiso (2500 pés), IV, Acc. 1999

Agradecimento. A Jorge Dutra Soledar, bolsista da Fundação de Amparo à Pesquisa do Estado do Rio Grande do Sul, pela execução das fotografias.

\section{REFERÊNCIAS BIBLIOGRÁFICAS}

Villiers, A. 1957. Démembrement du genre Cometes Serville. Descriptions des genres Pseudocometes, Paracometes, Microcometes nov. et des plusieurs espèces nouvelles (Col. Cerambycidae Disteniinae).

Bull. Mus. Natn Hist. nat., Paris, (2)29(5): 407-413.

—. 1958a. Révision du genre Paracometes Villiers. Revue fr. Ent., Paris, 25: 43-56.

- 1958b. Révision des genres Pseudometes Villiers et Heteropalpus Buquet (Col., Cerambycidae, Disteniinae). Bull. Soc. ent. Fr. Paris, 63: 37-40.

-.1959. Essai sur les Distenia américains (Col. Cerambycidae). Revue fr. Ent., Paris, 26(2): 55-76.

Recebido em 28.03.2000; aceito em 03.07.2000. 